\title{
Cardiovascular dynamics in women during the menstrual cycle and oral contraceptive therapy
}

\author{
W. A. L I T T LER, R. B O J O R G E S - B U E N O, \\ a n d J U D B A N K S \\ The Field Marshal Alexander Department of Cardiovascular Medicine, \\ Radcliffe Infirmary, Oxford
}

\begin{abstract}
Littler, W. A., Bojorges-Bueno, R., and Banks, Judy (1974). Thorax, 29, 567-570. Cardiovascular dynamics in women during the menstrual cycle and oral contraceptive therapy. Measurements of pulmonary blood flow and cardiac output have been made in 31 healthy women during the follicular and luteal phases of their menstrual cycle using nitrous oxide whole body plethysmography. The women were divided into three groups: 12 women were receiving oestrogen-progestogen contraceptive pills, 8 were receiving progestogen-only pills, and 11 were using either alternative methods of contraception or none at all. There was no significant difference in the values of cardiac index, pulmonary arterial distensibility, heart rate or systemic blood pressure during the two phases of the menstrual cycle in any of the three groups. When the three groups were compared the cardiac output showed the most significant difference, being greatest in the oestrogen-progestogen group, the progestogenonly group occupying an intermediate position. An increased cardiac output might play a part in the development of systemic hypertension in some women receiving oral contraceptives and could also add a risk to women with pre-existing heart disease.
\end{abstract}

An increased cardiac output has been reported in women receiving the oestrogen-progestogen contraceptive pill (Walters and Lim, 1969, 1970), while changes have been noted in both plasma and lung capillary volumes and in blood vessel distensibility during the luteal phase of the normal menstrual cycle (Seaton, 1972). We have now studied the pulmonary haemodynamics of women receiving both combined and progestogen-only contraceptive pills using nitrous oxide $\left(\mathrm{N}_{2} \mathrm{O}\right)$ body plethysmography.

\section{PATIENTS AND METHODS}

Thirty-one healthy, normotensive women were studied: 11 (group 1) were using either no contraception (5) or methods other than the pill (6); 12 (group 2) were taking combined oestrogen-progestogen contraceptive pills; and 8 (group 3) were taking progestogen-only oral contraceptives (Table I). Patients were recruited from a local family planning clinic with the exception of five control patients who were not using any form of contraception and were recruited from the hospital staff.

The three groups were studied concurrently under identical conditions. The subjects were studied on two separate occasions during their menstrual cycle-between 7 and 10 days after, and one to four days before the onset of bleeding-with the exception of four women taking the progestogen-only preparation who had grossly irregular and unpredictable bleeding and were studied at an interval of four weeks.

Arterial blood pressure was measured with a mercury sphygmomanometer after the subject had been lying at rest for 10 minutes. Heart rate was determined from the electrocardiogram during plethysmography.

N2O BODY PLETHYSMOGRAPHY Readings were taken with the patient in the supine position. All patients were trained to perform the respiratory manoeuvre in an identical manner and to maintain constant air flow during slow exhalation.

Pulmonary capillary blood flow was measured by the $\mathrm{N}_{2} \mathrm{O}$ uptake technique during slow exhalation after a single breath of $80 \% \mathrm{~N}_{2} \mathrm{O}$ and $20 \% \mathrm{O}_{2}$, according to the method of Bosman et al. (1964). Lead 2 of the electrocardiogram and a high-frequency phonocardiogram from the pulmonary area were recorded. The pattern of instantaneous pulmonary capillary blood-flow was derived from the $\mathrm{N}_{2} \mathrm{O}$ uptake by the method previously described (Karatzas and Lee, 1969).

A typical $\mathrm{N}_{2} \mathrm{O}$ plethysmograph record with an air control record superimposed upon it is shown diagrammatically (Figure). From this record right ventricular stroke volume could also be obtained from the integrated volume of $\mathrm{N}_{2} \mathrm{O}$ uptake. The pulsatility of lung-capillary blood-flow can be expressed as a ratio between the peak and the mean capillary blood-flow rate $\left(Q_{c} \max / Q_{c}\right)$. 
T A B L E I

\begin{tabular}{|c|c|c|c|c|c|}
\hline Case & Age & $\begin{array}{l}\text { BSA } \\
\left(m^{2}\right)\end{array}$ & Pill & $\begin{array}{c}\text { Duration } \\
\text { of Pill } \\
\text { (mth) }\end{array}$ & $\underset{\text { /Day }}{\text { Smoking }}$ \\
\hline \multicolumn{6}{|c|}{ Normals (Group1) } \\
\hline $\begin{array}{r}1 \\
2 \\
3 \\
4 \\
5 \\
6 \\
7 \\
8 \\
9 \\
10 \\
11\end{array}$ & $\begin{array}{l}29 \\
20 \\
31 \\
27 \\
24 \\
28 \\
19 \\
31 \\
22 \\
24 \\
27\end{array}$ & $\begin{array}{l}1.75 \\
1.79 \\
1.46 \\
1.46 \\
1.65 \\
1.61 \\
1.42 \\
1.54 \\
1.61 \\
1.53 \\
1.62\end{array}$ & $\begin{array}{l}\mathbf{A M} \\
\mathbf{O} \\
\mathbf{A M} \\
\mathbf{A M} \\
\mathbf{A M} \\
\mathbf{O} \\
\mathbf{A M} \\
\mathbf{A M} \\
\mathbf{O} \\
\mathbf{O} \\
\mathbf{O}\end{array}$ & $\begin{array}{l}- \\
- \\
z \\
z \\
- \\
- \\
-\end{array}$ & $\begin{array}{r}12 \\
0 \\
0 \\
5 \\
20 \\
0 \\
0 \\
0 \\
0 \\
0 \\
0\end{array}$ \\
\hline & $25 \cdot 6$ & $1 \cdot 59 \pm 0 \cdot 12$ & & - & \\
\hline
\end{tabular}

\begin{tabular}{|c|c|c|c|c|c|}
\hline \multicolumn{6}{|c|}{ Oestrogen-progestogen pill (Group 2) } \\
\hline $\begin{array}{r}1 \\
2 \\
3 \\
4 \\
5 \\
6 \\
7 \\
8 \\
9 \\
10 \\
11 \\
12\end{array}$ & $\begin{array}{l}21 \\
23 \\
21 \\
20 \\
24 \\
20 \\
26 \\
23 \\
20 \\
23 \\
17 \\
32\end{array}$ & $\begin{array}{l}1.70 \\
1.50 \\
1.74 \\
1.71 \\
1.40 \\
1.59 \\
1.64 \\
1.69 \\
1.60 \\
1.64 \\
1.47 \\
1.52\end{array}$ & $\begin{array}{l}\text { Ovran } \\
\text { Minilyn } \\
\text { Minilyn } \\
\text { Minovlar } \\
\text { Minovlar } \\
\text { Minilyn } \\
\text { Orthonovin 1/50 } \\
\text { Gynovlar 21 } \\
\text { Minovlar 21 } \\
\text { Orthonovin 1/50 } \\
\text { Minovlar } \\
\text { Norynil }\end{array}$ & $\begin{array}{r}30 \\
1 \\
36 \\
25 \\
29 \\
17 \\
24 \\
48 \\
5 \\
18 \\
24 \\
24\end{array}$ & $\begin{array}{r}0 \\
0 \\
40 \\
20 \\
0 \\
0 \\
0 \\
10 \\
0 \\
8 \\
17\end{array}$ \\
\hline & $22 \cdot 5$ & $1.61 \pm 0.1$ & & $23 \cdot 5$ & \\
\hline
\end{tabular}

\begin{tabular}{rl|l|l|r|r}
\multicolumn{3}{c|}{ Progestogen-only pill (Group 3) } & & \\
1 & 41 & 1.83 & Noriday & 24 & 0 \\
2 & 25 & 1.58 & Noriday & 11 & 0 \\
3 & 21 & 1.53 & Noriday & 17 & 0 \\
4 & 26 & 1.62 & Noriday & 12 & 20 \\
5 & 30 & 1.58 & Micronor & 4 & 5 \\
6 & 32 & 1.70 & Micronor & 6 & 0 \\
7 & 29 & 1.76 & Micronor & 9 & 0 \\
8 & 28 & 1.55 & Micronor & 6 & 0 \\
\hline & 29.0 & $1.64 \pm 0.11$ & & 11.0 & \\
\hline
\end{tabular}

AM: alternative methods of contraception.

The pulmonary artery to capillary flow conduction time $\left(\mathrm{C}_{\mathrm{t}}\right.$ in Figure) was measured as the time interval from the third major vibration of the first heart sound, indicating pulmonary valve opening, and the foot of the capillary flow pulse. The normal range for this conduction-time in this laboratory is 120-180 milliseconds. Measurements of $\mathrm{C}_{\mathrm{t}}$ made by different observers usually agree within 10 milliseconds.

\section{RESULTS}

Table II gives details of the physiological studies. Average pulse rates were higher in the pill groups compared with the controls, though not significantly so.

Cardiac output was significantly greater in group 2, compared with the control group, but not when compared with group 3. However, when expressed as cardiac index, this increased cardiac output did not achieve the same statistical significance when compared with the other two groups. Pulmonary artery capillary flow conduction time $\left(\mathrm{C}_{t}\right)$ and lung capillary blood flow pulsatility $\left(\mathrm{Q}_{\mathrm{c}} / \mathrm{Q}_{\mathrm{c}}\right)$ were slightly

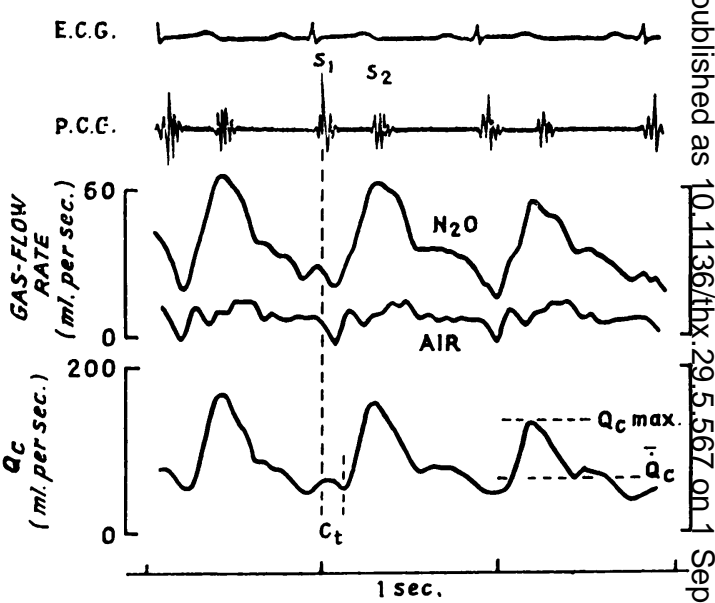

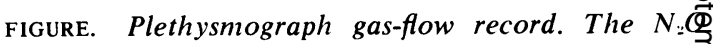
trace has been superimposed over the air record fromo a cardiac cycle of equal length and a similar portion of the respiratory cycle.

$E C G=$ electrocardiogram (lead 2); $P C G=$ phonocar diogram; $\mathrm{N}_{2} \mathrm{O}=$ plethysmograph gas-flow record during exhalation, after inhalation of $80 \% \quad N_{2} O$ in oxygen air = plethysmograph gas-flow record during exhalatio following inhalation of air; $Q_{\mathrm{c}}=$ the algebraic subtraco tion of $\mathrm{V}$ air from $\mathrm{V} \mathrm{N}_{2} \mathrm{O}$ for one cycle, calibrated $i$ blood-flow units; $C_{\mathrm{t}}=$ pulmonary artery to capillar $\$$ flow conduction time.

[Reproduced from Lancet (1973), 1274.]

less in group 3 when compared with the other tw? groups.

There was no significant difference in the values of any of the measurements during the luteal phase ơ the menstrual cycle compared with the follicula? phase.

\section{DISCUSSION}

Seaton (1972) has recently reviewed evidence whic suggests that there are significant changes within the cardiovascular system during the menstrual cycle An increase in plasma volume and a decrease iñ arterial and venous tone occurs during the luteal phase while there is vascular spasm immediatel premenstrually. In addition both Logan (1967) and Seaton (1972) have found an increased pulmonar capillary blood volume during the luteal phase which they attributed to distention of the pulmonaro capillary bed by progesterone, either alone or witf oestrogen, possibly secondary to an action on thळ arterioles or venules. Similar effects have been notes during pregnancy and in subjects taking oestrogene progestogen contraceptives (Seaton, 1972).

Our data show that there is no significant difference in heart rate, cardiac output, arterial pressure of 
T A B L E I I

\begin{tabular}{|c|c|c|c|c|c|c|c|c|c|c|c|}
\hline \multirow[t]{2}{*}{ Group } & \multicolumn{2}{|c|}{$\begin{array}{c}\text { Heart Rate } \\
(/ \mathrm{min})\end{array}$} & \multicolumn{2}{|c|}{$\begin{array}{c}\text { Cardiac Output } \\
(1 / \mathrm{min})\end{array}$} & \multicolumn{2}{|c|}{$\begin{array}{c}\text { Cardiac Index } \\
\left(1 / \mathrm{min} / \mathrm{m}^{2}\right)\end{array}$} & \multicolumn{2}{|c|}{$\begin{array}{c}\text { Pulm. Artery/ } \\
\text { Capillary } \\
\text { Conduction } \\
\text { Time (msec) }\end{array}$} & \multicolumn{2}{|c|}{$\frac{\mathbf{Q}_{\mathrm{c}}}{\mathbf{Q}_{\mathrm{c}}}$} & \multirow[t]{2}{*}{$\begin{array}{c}\text { Systemic } \\
\text { Arterial } \\
\text { Pressure } \\
\text { (mmHg) }\end{array}$} \\
\hline & $\mathbf{F}$ & L & $\mathbf{F}$ & $\mathbf{L}$ & F & $\mathbf{L}$ & $\mathbf{F}$ & L & $\mathbf{F}$ & $\mathbf{L}$ & \\
\hline $\begin{array}{l}\text { Normals } \\
\text { (11) }\end{array}$ & $71 \pm 11$ & $72 \pm 8$ & $5 \cdot 6 \pm 2 \cdot 6$ & $5 \cdot 5 \pm 2 \cdot 5$ & $3 \cdot 5 \pm 1 \cdot 8$ & $3 \cdot 4 \pm 1 \cdot 6$ & $138 \pm 21$ & $141 \pm 16$ & $1 \cdot 9 \pm 0 \cdot 3$ & $2 \cdot 1 \pm 0 \cdot 4$ & $\frac{111}{76} \pm \frac{7}{5} \quad \frac{111}{76} \pm \frac{7}{4}$ \\
\hline $\begin{array}{l}\text { Oestrogen- } \\
\text { progestogen } \\
\text { pills } \\
\text { (12) }\end{array}$ & $80 \pm 16$ & $80 \pm 15$ & $7 \cdot 9 \pm 2 \cdot 1^{1}$ & $7 \cdot 7 \pm 2 \cdot 3^{1}$ & $4 \cdot 5 \pm 1 \cdot 2$ & $4 \cdot 6 \pm 1 \cdot 4^{2}$ & $133 \pm 23$ & $130 \pm 24$ & $1 \cdot 7 \pm 0 \cdot 2$ & $1.9 \pm 0.3$ & $\frac{116}{77} \pm \frac{7}{6} \quad \frac{113}{77} \pm \frac{8}{6}$ \\
\hline $\begin{array}{l}\text { Progestogen- } \\
\text { only pills } \\
(8)\end{array}$ & $76 \pm 11$ & $74 \pm 11$ & $6 \cdot 7 \pm 1 \cdot 9$ & $7 \cdot 0 \pm 2 \cdot 5$ & $4 \cdot 1 \pm 1 \cdot 3$ & $4 \cdot 2 \pm 1 \cdot 4$ & $120 \pm 13$ & $122 \pm 9$ & $1 \cdot 7 \pm 0 \cdot 1$ & $1 \cdot 7 \pm 0 \cdot 2$ & $\frac{114}{74} \pm \frac{10}{8} \frac{116}{75} \pm \frac{7}{12}$ \\
\hline
\end{tabular}

Figures expressed as means \pm 1 SD.

Differences from normal values (Student's $t$ test): ${ }^{1} \mathrm{p}<0.25{ }^{2} \mathrm{p}<0.05$. $\mathbf{F}=$ follicular $; \mathbf{L}=$ luteal.

pulmonary arterial compliance during a normal menstrual cycle or one influenced by oral contraceptives. Thus whatever vascular changes occur during the luteal phase, they are not of sufficient magnitude to alter overall cardiac function.

The values for cardiac output derived from pulmonary blood flow measurements in the present study show that patients taking combined oral contraceptive preparations have a higher cardiac output than women who are not taking such pills. This finding is in keeping with the data of Walters and Lim (1969), which showed significant increases in cardiac output (expressed as cardiac index) in six young women during two to three months' therapy with oestrogen-progestogen contraceptives. When expressed as cardiac index our results do not achieve quite the significance of the values of cardiac output alone. Women in groups 2 and 3 had slightly larger body surface areas than those in group 1; weight gain is sometimes a problem for women on oral contraceptives.

Our values for cardiac indices were lower than those reported by Walters and Lim (1970), who used the photoelectric earpiece dye-dilution technique for measuring cardiac output. The $\mathrm{N}_{2} \mathrm{O}$ uptake technique measures pulmonary blood flow and required normal ventilation/perfusion relationships. Seaton (1972) has suggested that if a state of pulmonary vasodilatation exists in subjects on oral contraceptives, arteriovenous shunts may become opened. Such a situation might diminish $\mathrm{N}_{2} \mathrm{O}$ uptake and so produce lower values for cardiac output, although we doubt if this is a significant factor.

The increased cardiac output is due predominantly to an increased stroke volume. It is interesting that the results for heart rate and cardiac output in group 3 fall between the values in the other two groups; it is tempting to suggest that these results demonstrate a summation effect of progestogen and oestrogen. Walters and Lim (1970) have suggested that the increased cardiac output may be due to a direct stimulant effect of oestrogen on the myocardium or to an increased venous return associated with the observed increase in plasma volume. Similar changes in cardiac output and heart rate are known to occur during pregnancy and cannot be accounted for by placental 'shunting'.

The pulmonary artery to capillary flow conduction time $\left(C_{t}\right)$ is determined by the average path length between the pulmonary valve and the gas-exchanging vessels, and the average pulse wave velocity in the pulmonary arteries. The $C_{t}$ has been shown to correlate well with mean pulmonary artery pressure in patients with normal and raised pulmonary artery pressures (Reuben, 1970). There was no change in the level of $C_{t}$ during the menstrual cycle in any of our three groups. In group 2 , the $C_{t}$ was not significantly different from group 1 , indicating dilatation of the pulmonary arterial system in response to the increased pulmonary blood flow.

High cardiac output may well be one factor contributing to the development of systemic hypertension in some women taking oral contraceptives (Walters and Lim, 1970); the peripheral vascular resistance may increase to reduce the cardiac output but at the cost of a raised arterial pressure. (None of our patients had developed hypertension.) Women with cardiac disease or coronary risk factors are usually advised against using oral contraceptives because of thrombotic risks; our data suggest that the combined pill particularly may also be harmful because of increased cardiac work.

We thank Dr. Grant Lee for allowing us to use the facilities of his laboratory; Mr. Terence Stallard and Mrs. Elsie Wheeler for technical assistance; and Mr. John Bonnar, Dr. John Guillebaud, and Dr. M. Corrie for allowing us to study patients under their care. 
Dr. Bojorges-Bueno was supported by a grant from the National Heart Institute of Mexico.

\section{REFERENCES}

Bosman, A. R., Honour, A. J., Lee, G. de J., Marshall, R., and Stott, F. D. (1964). A method for measuring instantaneous pulmonary capillary blood flow and right ventricular stroke volume in man. Clinical Science, 26, 247.

Karatzas, N. B. and Lee, G. de J. (1969). Propagation of blood flow pulse in the normal human pulmonary arterial system. Circulation Research, 25, 11.

Logan, W. F. W. E. (1967). The pulmonary capillary bed in pregnancy and mitral stenosis. M.D. Thesis, University of Liverpool.
Reuben, S. R. (1970). Wave transmission in the pulmonary arterial system in disease in man. Circulation Research, 27, 523.

Seaton, A. (1972). Pulmonary capillary blood volume in women: normal values and the effect of orats contraceptives. Thorax, 27, 75.

Walters, W. A. W. and Lim, Y. L. (1969). Cardiovascular dynamics in women receiving ora contraceptive therapy. Lancet, $2,879$. and - (1970). Haemodynamic changes in women taking oral contraceptives. Journal of Obstetrics and Gynaecology of the British Com $\approx$ monwealth, 77, 1007.

Requests for reprints to: Dr. W. A. Litter, The Radcliffe Infirmary, Oxford. 